\title{
Knock-down of protein L-isoaspartyl 0-methyltrans- ferase increases $\beta$-amyloid production by decreasing ADAM10 and ADAM17 levels
}

\author{
Narkhyun BAE ${ }^{1}$, Se Eun BYEON ${ }^{1}$, Jihyuk SONG ${ }^{1}$, Sang-Jin LEE ${ }^{1}$, Moosik KWON ${ }^{1}$, Inhee MOOK-JUNG ${ }^{2}$, Jae Youl CHO ${ }^{1}$, \\ Sungyoul $\mathrm{HONG}^{1, *}$ \\ ${ }^{1}$ Department of Genetic Engineering, Sungkyunkwan University, Suwon 440-746, Republic of Korea; ${ }^{2}$ Department of Biochemistry and \\ Cancer Research Institute, Seoul National University College of Medicine, Seoul 110-799, Republic of Korea
}

Aim: To examine the role of protein L-isoaspartyl O-methyltransferase (PIMT; EC 2.1.1.77) on the secretion of AB peptides. Methods: HEK293 APPsw cells were treated with PIMT siRNA or adenosine dialdehyde (AdOX), a broad-spectrum methyltransferase inhibitor. Under the conditions, the level of $A \beta$ secretion and regulatory mechanism by PIMT were examined.

Results: Knock-down of PIMT and treatment with AdOX significantly increased $A \beta_{40}$ secretion. Reductions in levels of PIMT decreased the secretion of soluble amyloid precursor protein alpha (SAPP $\alpha$ ) without altering the total expression of APP or its membrane-bound C83 fragment. However, the levels of the $C 99$ fragment generated by $\beta$-secretase were enhanced. Moreover, the decreased secretion of SAPP $\alpha$ resulting from PIMT knock-down seemed to be linked with the suppression of the expression of $\alpha$-secretase gene products, $\alpha$-disintegrin and metalloprotease 10 (ADAM10) and ADAM17, as indicated by Western blot analysis. In contrast, ADAM10 was not down-regulated in response to treatment with the protein arginine methyltransferase (PRMT) inhibitor, AMI-1.

Conclusion: This study demonstrates a novel role for PIMT, but not PRMT, as a negative regulator of A $\beta$ peptide formation and a potential protective factor in the pathogenesis of $A D$.

Keywords: Alzheimer's disease; $\beta$-amyloid protein; L-isoaspartyl O-methyltransferase; soluble amyloid precursor protein alpha; ADAM10; ADAM17

Acta Pharmacologica Sinica (2011) 32: 288-294; doi: 10.1038/aps.2010.228

\section{Introduction}

Alzheimer's disease (AD), the most common neurodegenerative disease, is characterized by progressive memory loss and other cognitive impairments ${ }^{[1,2]}$. Neuropathological hallmarks of $\mathrm{AD}$ include the deposition of amyloid beta $(\mathrm{A} \beta)$ peptides, which are organized in senile plaques. In addition, AD is characterized by the accumulation of phosphorylated tau proteins, which are arranged in neurofibrillary tangles (NFTs $)^{[2]}$. $\mathrm{A} \beta$ peptides are generated through the proteolysis of the amyloid precursor protein (APP). In the amyloidogenic pathway, $\beta$-secretase cleaves APP to produce soluble amyloid precursor protein beta sAPP $\beta$ and a C99 fragment. Membrane-bound C99 can be further processed by $\gamma$-secretase to produce A $\beta$ peptides $^{[3,4]}$. As an alternative, non-amyloidogenic pathway, a-secretase can cleave within the $A \beta$ region to produce a

\footnotetext{
* To whom correspondence should be addressed.

E-mail syhong@skku.edu

Received 2010-09-26 Accepted 2010-12-17
}

sAPPa fragment and a C83 fragment ${ }^{[4]}$.

High levels of homocysteine (HCY) can lead to increased concentrations of $S$-adenosylhomocysteine (SAH), a strong methyltransferase inhibitor ${ }^{[5]}$. This up-regulation of SAH results in an overall decrease in the activity of $S$-adenosylmethionine (SAM)-dependent methyltransferases. Increased SAH levels in the brain tissue of patients with AD has been associated with the inhibition of catechol-O-methyltransferase (COMT) and phenylethanolamine- $N$-methyltransferase (PNMT), two enzymes that are widely distributed throughout the human brain ${ }^{[6]}$. Treatment of Neuro-2a neuroblastoma cells with SAH has been shown to inhibit protein phosphatase 2A methyltransferase (PPMT), resulting in decreased methylation of protein phosphatase $2 \mathrm{~A}^{[7]}$. SAH treatment has also been associated with the increased accumulation of APP and phosphorylated tau and with increased $A \beta$ secretion $^{[8]}$. Protein $L$-isoaspartyl methylation is also essential for the maintenance of neural activity in the central nervous system (CNS). Deficiency of protein $L$-isoaspartyl O-methyltransferase (PIMT, 
EC2.1.1.77), an enzyme that catalyzes the transfer of an active methyl group from SAM to L-isoaspartate and D-isoaspartate, leads to fatal progressive epileptic disease ${ }^{[9]}$. Alterations in the SAM/SAH ratio, which is relevant to the overall excitatory state of neurons, have been reported in PIMT-deficient mice ${ }^{[10]}$. Previous studies have identified deposits of $A \beta$ peptides with isoaspartates in brain tissue isolated from AD patients and PIMT knock-out mice, suggesting a potential pathophysiological role in progressive neurodegeneration ${ }^{[10,11]}$. In patients with AD, PIMT is up-regulated in degenerating neurons and is localized in NFTs ${ }^{[10]}$. Despite the increasing evidence supporting a role for PIMT in neurodegeneration, the mechanism by which PIMT modulates $\mathrm{A} \beta$ peptide generation in AD pathogenesis remains unclear. To uncover the mechanism whereby PIMT exerts its effects, we examined the ability of PIMT to regulate $\mathrm{A} \beta$ secretion in vitro.

\section{Materials and methods}

\section{Antibodies and reagents}

Adenosine dialdehyde (AdOX), SAM, and mouse anti- $\beta$-actin antibodies were purchased from Sigma-Aldrich Chemicals (St Louis, MO, USA). AMI-1 was obtained from Calbiochem (La Jolla, CA, USA). Dulbecco's modified Eagle's medium (DMEM), Opti-MEM, Dulbecco's phosphate buffered saline (DPBS), penicillin, streptomycin, and fetal bovine serum (FBS) were purchased from Gibco (Carlsbad, CA, USA). 3-(4,5-Dimethylthiazol-2-yl)-2,5-diphenyltetrazolium bromide (MTT) was obtained from Calbiochem (La Jolla, CA, USA). Moloney Murine Leukemia virus (M-MLV) reverse transcriptase and polymerase chain reaction (PCR) premix was purchased from Rexgene Biotech Co, Ltd (Ochang, Korea). All of the primers used for PCR were purchased from Bioneer (Daejeon, Korea). A mixture of Stealth ${ }^{\mathrm{TM}} /$ siRNA duplex oligoribonucleotides against PIMT and Lipofectamine ${ }^{\mathrm{TM}}$ RNAiMAX were purchased from Invitrogen (Carlsbad, CA, USA). Monoclonal mouse anti-APP (6E10) antibody was obtained from Signet Laboratories (Dedham, MA, USA). Polyclonal rabbit antibodies to ADAM9, ADAM10, and ADAM17 were obtained from Chemicon International (Temecula, CA, USA). Monoclonal mouse BACE1, monoclonal anti-mouse horseradish peroxidase (HRP)-conjugated secondary antibodies, and anti-rabbit HRPconjugated secondary antibodies were purchased from Santa Cruz Biotechnology (Santa Cruz, CA, USA). Rabbit anti-PIMT antisera was produced against recombinant porcine PIMT proteins as described ${ }^{[12]}$. The Genbank nucleotide sequence database accession number of the nucleotide sequence of the clone is AF239700.

\section{Cell culture, drug treatment, and protein preparation}

HEK293 APPsw and SH-SY5Y cells were plated on 100-mm culture dishes (Corning Incorporated, Corning, NY, USA). The dishes were filled with DMEM containing 10\% FBS, 100 units/mL penicillin, and $100 \mu \mathrm{g} / \mathrm{mL}$ streptomycin. The cultures were maintained at $37{ }^{\circ} \mathrm{C}$ with $5 \% \mathrm{CO}_{2}$ under humidified conditions. Cells were treated with drugs (SAM, AdOX, and AMI-1) for indicated times. Vivaspin20 centrifugal filter devices (Satorius, Goettingen, Germany) were used to concentrate conditioned media (CM) from HEK293 APPsw and SH-SY5Y cells collected after drug or siRNA treatments. Cells were washed with DPBS and lysed in Pro-Prep ${ }^{\mathrm{TM}}$ protein extraction buffer for $20 \mathrm{~min}$ on ice. The protein concentration of each sample was quantified using a Bradford assay (BioRad, Hercules, CA, USA).

\section{Cell viability assay}

To determine cell viability, cells were plated on 96-well plates at a density of $2 \times 10^{4}$ cells per well. The original media was then replaced with media containing MTT at a final concentration of $0.5 \mathrm{mg} / \mathrm{mL}^{[13]}$. Four hours later, the medium was discarded, and DMSO was added for the colorimetric assay. Absorption values were determined using an $E_{\max }$ microplate reader from Molecular Devices (Union City, CA, USA) with a 540-nm filter.

\section{Reverse transcriptase-polymerase chain reaction}

RNA was isolated from HEK293 APPsw cells treated with or without PIMT siRNA using TRIzol reagent (Gibco BRL) according to the manufacturer's instructions. For each RTPCR reaction, $1 \mu \mathrm{g}$ of RNA was used. Each sample was preheated to $60{ }^{\circ} \mathrm{C}$ with oligo $(\mathrm{dT})_{18}$ primers for $10 \mathrm{~min}$. One unit per milliliter of M-MLV reverse transcriptase was added. The reaction was then performed at $37^{\circ} \mathrm{C}$ for $60 \mathrm{~min}$ with the following primers: PIMT, forward 5'-TCAGGAAGGACGATCCAACA-3', reverse 5' -TCCTCCGGGCTTTAACTGAT-3'; and GAPDH, forward 5'-AAGGGTCATCATCTCTGCCC-3', reverse 5'-GTGATGGCATGGACTGTGGT-3'. Amplification was carried out for 20 to 30 cycles with the following parameters: $94{ }^{\circ} \mathrm{C}$ for $30 \mathrm{~s}, 55-57^{\circ} \mathrm{C}$ for $40 \mathrm{~s}$, and $72{ }^{\circ} \mathrm{C}$ for $30 \mathrm{~s}$. These steps were followed by a final 5 min extension step at $72{ }^{\circ} \mathrm{C}$.

\section{siRNA transfection}

To conduct the PIMT siRNA transfection, 500000 cells were seeded onto $100-\mathrm{mm}$ culture plates. Cells were cultured for $48 \mathrm{~h}$ at $37{ }^{\circ} \mathrm{C}$ in culture medium containing serum, which allowed the cells to be approximately $80 \%$ confluent. Immediately prior to transfection, lipofectamine RNAiMAX was incubated with the siRNA of interest in OPTI-MEM (Gibco) at room temperature for $10 \mathrm{~min}$. The cells were then incubated in this mixture for $48 \mathrm{~h}$ at $37^{\circ} \mathrm{C}$ in fresh medium containing serum.

\section{Immunoblotting}

Twenty micrograms of protein mixed with $5 \times$ loading buffer [0.313 mol/L Tris- $\mathrm{HCl}$ (pH 6.8), 10\% SDS, 0.05\% bromophenol blue, $50 \%$ glycerol], and $20 \times$ reducing agent $(2 \mathrm{~mol} / \mathrm{L}$ DTT: Fermentas, Hanover, MD, USA) were boiled for $5 \mathrm{~min}$ and loaded onto a $10 \%$ SDS-polyacrylamide gel. After electrophoresis, proteins were transferred to a polyvinylidene fluoride (PVDF) membrane (Millipore, Billerica, MA, USA). The membranes were blocked with $5 \%$ non-fat milk in $20 \mathrm{mmol} / \mathrm{L}$ Tris$\mathrm{HCl}$ (pH 7.4) containing $150 \mathrm{mmol} / \mathrm{L} \mathrm{NaCl}$ and $0.1 \%$ Tween 20 (TBS-T). They were then incubated overnight at $4{ }^{\circ} \mathrm{C}$ with 
primary antibodies (1:2000 for 6E10, 1:1000 for 22C11, 1:3000 for $\beta$-actin, 1:2000 for ADAM10, 1:1000 for BACE1, 1:3000 for PIMT) in non-fat milk. The membranes were washed for 10 min in TBS-T and then incubated for $2 \mathrm{~h}$ in non-fat milk at room temperature with horseradish peroxidase-conjugated anti-mouse/rabbit secondary antibodies. Bound antibodies were visualized with an enhanced chemiluminescence detection kit (Amersham Bioscience, Pittsburgh, PA, USA).

\section{Cell surface biotinylation}

HEK 293 APPsw cells were surface biotinylated by incubation with $2 \mathrm{mg} / \mathrm{mL}$ Sulfo-NHS-SS-Biotin (Pierce, Rockford, IL, USA) in ice-cold PBS. After $30 \mathrm{~min}$, the cells were washed and quenched with PBS containing $100 \mathrm{mmol} / \mathrm{L}$ glycine. Cells were lysed in 1\% NP-40 buffer and incubated with Neutravidin $^{\mathrm{TM}}$ immobilized onto $6 \%$ cross-linked beaded agarose (Pierce). The beads were washed in NP-40 buffer, boiled in sample buffer, separated using SDS-PAGE, and immunoblotted with the indicated antibodies.

\section{$A \beta_{40}$ ELISA assay}

A variety of $A \beta$ peptides, ranging from 38 to 43 amino acids in length, have been shown to be secreted in response to $\gamma$-secretase activation ${ }^{[14,15]} . A \beta_{42}$ is the peptide most widely implicated in AD pathogenesis ${ }^{[16]}$; however, the antibody for $A \beta_{40}$ was selected based on its reproducibility and accuracy in the $A \beta_{40}$ ELISA kit. The CM was cleared of debris, and the secreted $A \beta_{40}$ was measured using a sandwich ELISA kit (Signet Laboratory, Dedham, MA, USA) according to the manufacturer's instructions.

\section{Statistical analysis}

Quantitative analysis of Western blotting was performed by calculating the relative density of immunoreactive bands. The data are expressed as a percentage of the control values. Data are presented as the mean $\pm S D$. Each procedure was performed in three to five independent experiments. A Student's $t$-test analysis was used to evaluate statistical significance.

\section{Results}

PIMT siRNA and AdOX induce $A \beta$ secretion in HEK293 APPsw cells

As shown in Figure 1A and 1B, PIMT siRNA transfection and AdOX treatment increased the secretion of $A \beta_{40}$ in HEK293 APPsw cells approximately two fold. Compared to controls, PIMT siRNA induced a $35.6 \% \pm 8.0 \%$ reduction in mRNA and protein levels in HEK293 APPsw cells $48 \mathrm{~h}$ after transfection (Figure 1C). Importantly, the concentration of AdOX used was not cytotoxic (Figure 1D).

PIMT siRNA transfection and AdOX decreases SAPP $\alpha$ secretion and increases C99 in HEK293 APPsw cells

To understand the molecular mechanism of PIMT siRNAmediated $A \beta_{40}$ secretion, we evaluated whether PIMT played a role in the processing of APP. To do this, we measured the levels of the APP cleavage products: sAPPa, C99, and C83.
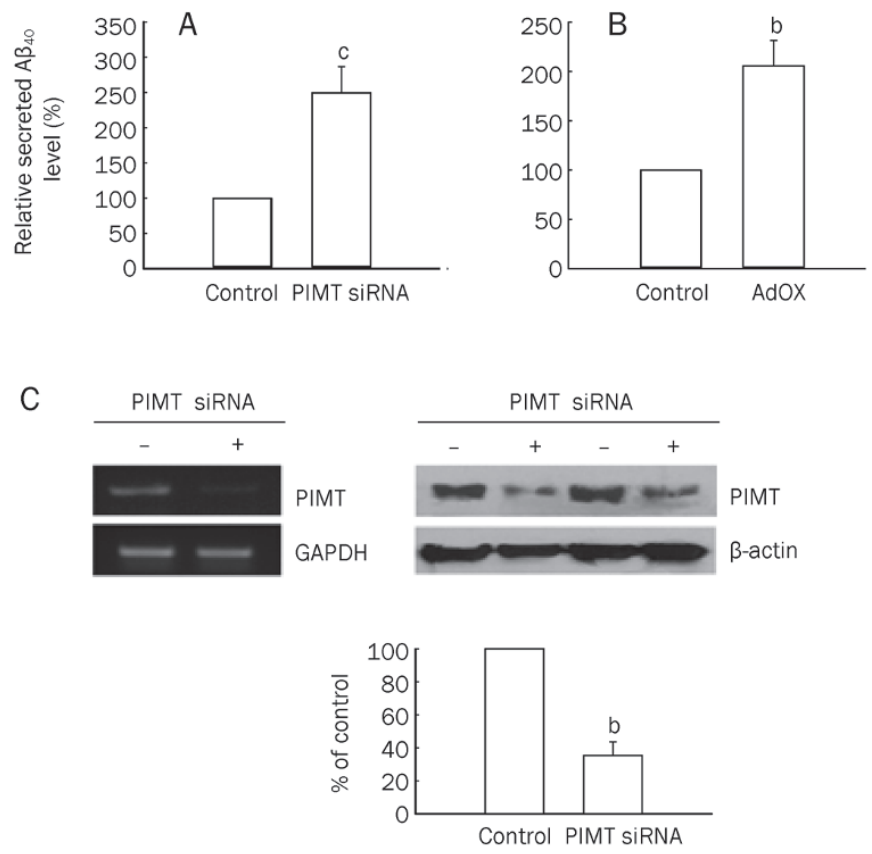

D

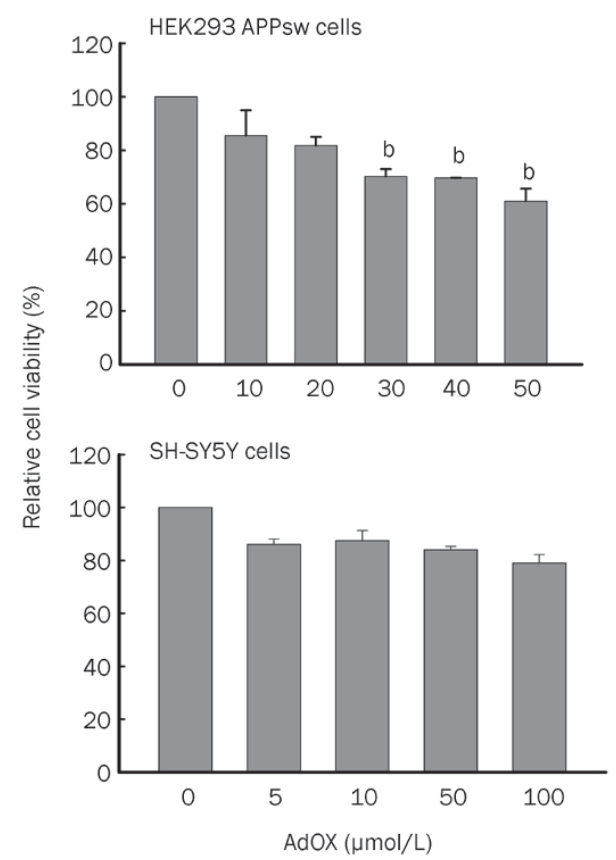

Figure 1. The effects of PIMT siRNA and AdOX treatments on $A \beta$ production. (A and B) HEK293 APPsw cells were treated with or without PIMT siRNA and AdOX. The levels of $A \beta_{40}$ peptide were analyzed using ELISA. (C) HEK293 APPsw cells were transiently transfected with PIMT SiRNA at a concentration of $30 \mathrm{nmol} / \mathrm{L}$. RT-PCR of RNA isolated at $48 \mathrm{~h}$ shows PIMT mRNA levels were reduced by PIMT siRNA. As a loading control, GAPDH mRNA levels were examined in HEK293 APPsw cells. Expression levels of PIMT protein were analyzed using a Western blot with rabbit anti-PIMT antiserum. As a loading control, levels of $\beta$-actin were also determined. (D) HEK293 APPsw cells and SH-SY5Y cells were treated with AdOX. Cell viability was determined using an MTT assay. Results are expressed as the mean $\pm S D$ for three independent experiments. Mean \pm SD. ${ }^{b} P<0.05,{ }^{c} P<0.01$ compared to untreated or control group. 
A

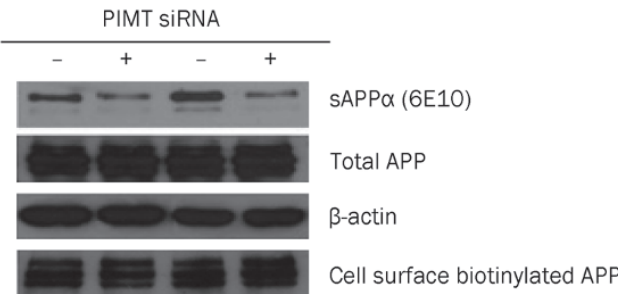

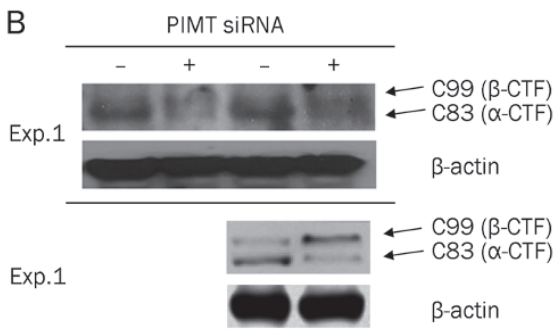

C

\begin{tabular}{|c|c|c|c|c|}
\hline \multicolumn{5}{|c|}{ Upper panel } \\
\hline \multicolumn{4}{|c|}{ AdOX } & \\
\hline \multicolumn{2}{|c|}{ SWHEK } & \multicolumn{2}{|c|}{ SH-SY5Y } & \\
\hline 0 & 20 & 0 & 100 & $\mu \mathrm{mol} / \mathrm{L}$ \\
\hline & $=$ & 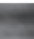 & & sAPP $\alpha(6 \mathrm{E} 10)$ \\
\hline & & & & Total APP \\
\hline & & & & $\beta$-actin \\
\hline
\end{tabular}

Lower panel

\begin{tabular}{|c|c|c|c|c|}
\hline \multicolumn{4}{|c|}{ SAM } & \\
\hline & & & Y5Y & \\
\hline 0 & 100 & 0 & 100 & $\mu \mathrm{mol} / \mathrm{L}$ \\
\hline
\end{tabular}
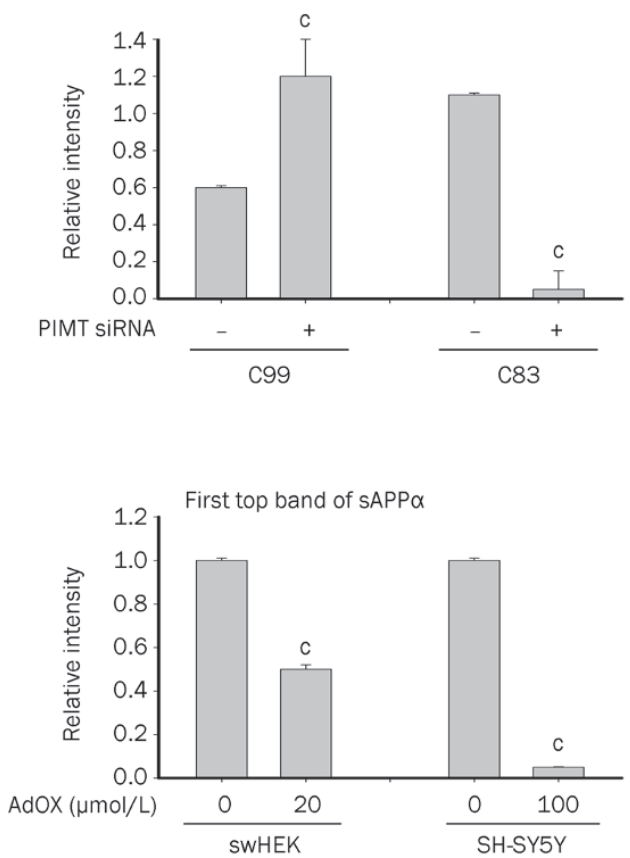

Figure 2. The effects of PIMT siRNA, AdOX, and SAM treatments on levels of membrane bound APP, total APP, and sAPP $\alpha$. (A) The accumulation of SAPP $\alpha$ in the concentrated media, total cellular and membrane-bound levels of APP, C83, and $C 99$ were analyzed by Western blot analysis. (B) HEK293 APPsw cells were transiently transfected with PIMT siRNA at a concentration of $30 \mathrm{nmol} / \mathrm{L}$. The levels of C99 and C83 proteins were analyzed using Western blotting. As a loading control, levels of $\beta$-actin were also determined. (C) HEK293 APPsw (swHEK) and SH-SY5Y cells were incubated without or with AdOX $(20 \mu \mathrm{mol} / \mathrm{L})$ and $\operatorname{SAM}(100 \mu \mathrm{mol} / \mathrm{L})$ for $24 \mathrm{~h}$. The levels of SAPP $\alpha$ in the concentrated media, total cellular APP, and membrane-bound APP were analyzed by Western blot analysis. Mean \pm SD. ${ }^{b} P<0.05,{ }^{c} P<0.01$ compared to normal group.
Western blotting for sAPPa in the CM revealed that PIMT siRNA decreased the secretion of sAPPa by $67.4 \% \pm 3.4 \%$. However, the overall expression of total APP and biotinlabeled membrane APP remained unchanged (Figure 2A), suggesting that the amount of SAPP $\beta$, a critical component for secretion of $A \beta_{40}$, might be increased. Indeed, the C99 fragment, the cleavage product of $\beta$-secretase ${ }^{[17]}$, was increased in PIMT siRNA-treated cells. At the same time, C83 was decreased in PIMT transfected cells (Figure 2B). Similar patterns of sAPPa and total APP were also observed in the AdOX treatment group (Figure 2C, upper panel). In contrast, the induction of transmethylation with $100 \mu \mathrm{mol} / \mathrm{L}$ SAM, a methyl donor ${ }^{[5]}$, increased sAPPa in both cell types (Figure 2C lower panel), demonstrating a critical role of transmethylation in APP processing.

PIMT siRNA transfection decreases ADAM10 and ADAM17 expression

A decrease in SAPPa without a corresponding reduction in total APP expression suggests a potential alteration in the expression or activity of APP processing enzymes. To investigate whether PIMT siRNA altered the expression of APP processing enzymes, we measured the expression levels of several a-secretase candidates: ADAM9, ADAM10, and ADAM17; and the $\beta$-secretase candidate, BACE1. As shown in Figure 3A, PIMT siRNA reduced the expression of both the mature and the immature forms of ADAM 10 by $45 \%$ to $55 \%$ compared to controls. In contrast, PIMT siRNA did not significantly 
A

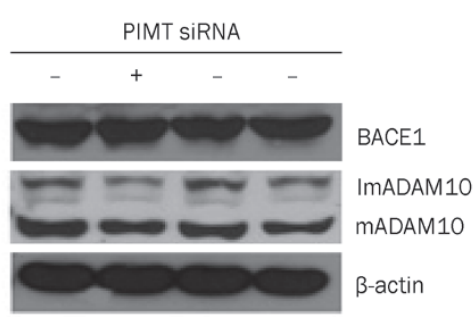

B

\begin{tabular}{rlllll} 
B & \multicolumn{5}{c}{$48 \mathrm{~h}$} \\
\cline { 2 - 6 } Control siRNA $(30 \mathrm{nmol} / \mathrm{L})$ & + & - & + & - \\
PIMT2 $(30 \mathrm{nmol} / \mathrm{L})$ & - & + & - & - \\
PIMT3 $(30 \mathrm{nmol} / \mathrm{L})$ & - & - & - & +
\end{tabular}

Im ADAM9

Im ADAM17

PIMT

$\beta$-actin

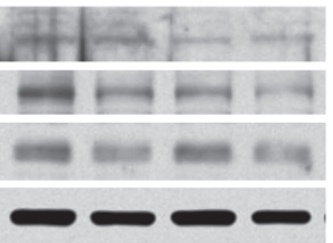

C

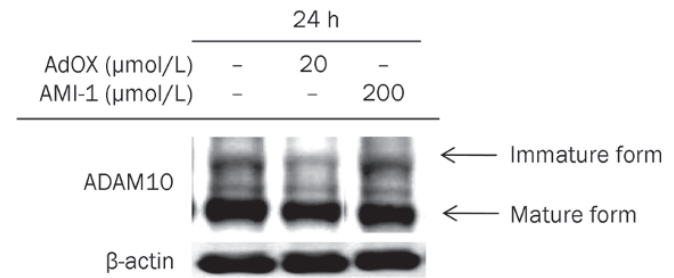

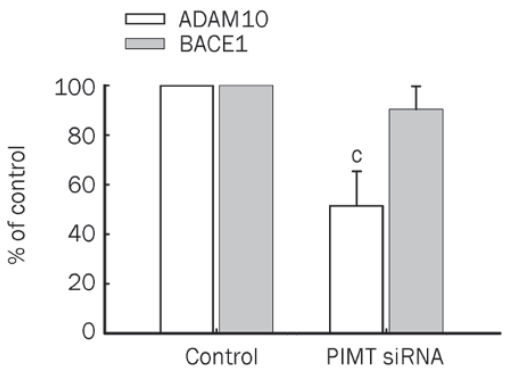
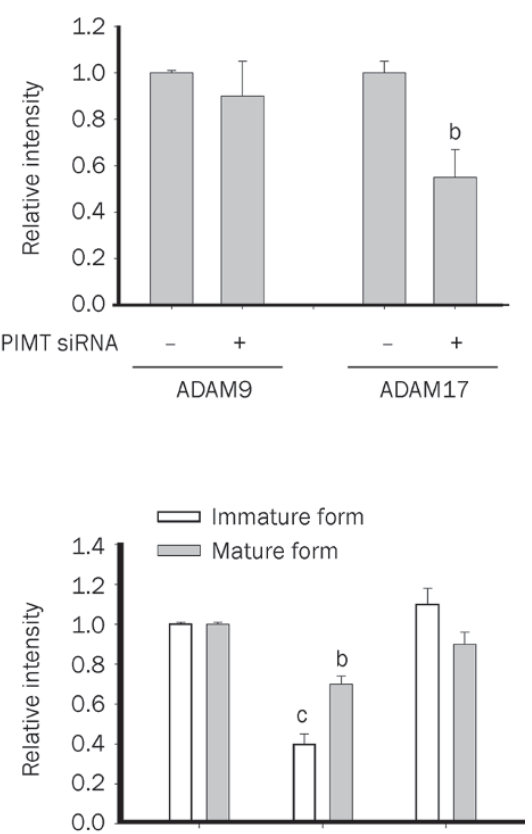

Figure 3. The effects of PIMT siRNA on ADAM10 and BACE1 expression levels. (A) HEK293 APPsw cells were treated with PIMT siRNA for 48 h. Cells were then harvested, and the protein levels of BACE1 and immature (ImADAM10) and mature (mADAM10) forms of ADAM10 were analyzed by Western blot analysis. Densitometric analysis was performed to determine the relative protein level of immature ADAM10 and BACE1. Results are expressed as the mean $\pm S D$ for three independent experiments. (B) HEK293 APPsw cells were treated with PIMT siRNA for $48 \mathrm{~h}$. Cells were then harvested, and the protein levels of immature ADAM9 and ADAM17, as well as PIMT were analyzed by Western blot analysis. Densitometric analysis was performed to determine the relative protein level of immature ADAM9 and ADAM17. (C) HEK293 APPsw cells were treated with AdOX or AMI-1 for 24 h. Cells were then harvested and the protein levels of immature and mature ADAM10 were analyzed by Western blotting analysis compared to control. Densitometric analysis was performed to determine the relative level of immature and mature ADAM10. Mean \pm SD. ${ }^{b} P<0.05,{ }^{c} P<0.01$ compared to normal group.

alter the levels of BACE1 $(90.4 \% \pm 14 \%$ compared to control). PIMT siRNA treatment down-regulated the total protein levels of ADAM17, but not ADAM9 (Figure 3B). In agreement with these data, AdOX, but not AMI-1, a PRMT inhibitor, also strongly reduced ADAM10 levels (Figure 3C). These results suggest that PIMT, but not PRMT, selectively modulates the protein levels of ADAM10 and ADAM17.

\section{Discussion}

In this study, we used HEK293 APPsw cells and SH-SY5Y cells to investigate the effects of protein L-isoaspartyl methylation on APP processing. HEK293 APPsw cells express high levels of $A \beta^{[18]}$, and SH-SY5Y human neuroblastoma cells express considerable levels of APP and secrete non-toxic, non-amyloidogenic $\mathrm{SAPP}^{[17]}$. Because of this, these cell lines have been widely used to study the regulation of APP processing related to the pathogenesis of $\mathrm{AD}^{[19]}$. Therefore, we used these cells in our study to examine the regulatory role of transmethylation on APP processing. Interestingly, treatment of either cell type with PIMT siRNA and AdOX, a well-known inhibitor of transmethylation ${ }^{[20]}$, remarkably induced the release of $A \beta_{40}$ peptides (Figure 1), indicating the involvement of PIMT-mediated methylation in APP cleavage. Because numerous papers have shown that the secretion of $A \beta_{40}$ is accompanied by the release of additional $\gamma$-secretase-generated $A \beta$ peptides, such as $A \beta_{38}$, $A \beta_{42}$, and $A \beta_{43}$, it is likely that the production of these peptides would also be regulated by PIMT siRNA treatment.

To investigate the molecular mechanism underlying this phenomenon, the levels of the enzyme that generate $A \beta_{40}$ peptides were first determined. Figures 2 and 3 reveal that PIMT 
knock-down modulates both the secretion and cleavage of sAPPa. In response to PIMT siRNA treatment, sAPPa secretion was dramatically diminished, but the levels of total APP and membrane-bound biotinylated APP remained unchanged (Figure 2A). These results suggest that $\mathrm{AAPP} \beta$ might be relatively enhanced by PIMT siRNA. The C99 fragment, a $\beta$-secretase cleavage product of APP, was increased by PIMT knock-down, whereas C83 was dramatically diminished (Figure $2 \mathrm{~B}$ ). Overall, our results suggest that the PIMT-mediated $\mathrm{A} \beta_{40}$ production pathway might be primarily associated with the sAPPa cleavage pathway. It has been reported that green tea polyphenol (-)-epigallocatechin-3-gallate (EGCG) exerts a beneficial role in reducing brain $A \beta$ levels by promoting the cleavage of the C99 fragment of APP. The corresponding elevation of sAPPa ${ }^{[21]}$ and G-protein coupled signaling, a major excitatory signal transduction pathway in neuronal cells, is known to activate a sAPPa generation pathway ${ }^{[22]}$. Therefore, PIMT knock-down could contribute to the down-regulation of sAPPa during $A \beta_{40}$ production.

The improper production of APP isoforms or aberrant APP trafficking during AD pathogenesis is believed to favor the amyloidogenic pathway ${ }^{[23]}$. In addition, recent reports have shown that $A \beta$ production is influenced more by the location of APP cleavage than the total amount of secretase present within the cell ${ }^{[24]}$. However, in our study, neither the total amount of APP nor the amount of membrane-associated APP (Figure 2A) was altered in response to PIMT siRNA treatment. These results imply that PIMT does not regulate the trafficking of APP to the cell membrane or its synthesis. Instead, the protein levels of $A \beta_{40}$ generating enzymes (Figure 3 ) clearly reveal an involvement of proteolytic processing in the observed decrease in SAPPa and increase in $\mathrm{A} \beta_{40}$ peptides in response to PIMT siRNA. Indeed, the expression of the a-secretase gene products, a-disintegrin and metalloprotease 10 (ADAM10) and ADAM17 $7^{[21]}$, was reduced after PIMT siRNA transfection in HEK293 APPsw cells according to Western blot analysis (Figure 3). The facts that BACE1 expression was not altered (Figure 3A) and that the PRMT inhibitor, AMI-1, did not affect ADAM10 levels (Figure 3C) seem to highlight the specificity of this pathway leading to $A \beta_{40}$ generation. However, we cannot exclude the possibility that PIMT knock-down leads to the direct activation of BACE1 despite not affecting its expression level. Indeed, previous work has shown that BACE1-inducible cells exhibit increased production of $A \beta_{40}$ peptides $^{[25]}$. To date, there is no experimental evidence suggesting that PIMT can regulate the enzyme activity of BACE1. However, several studies have reported that BACE1 can be modified by S-palmitoylation $^{[26]}$ and ubiquitination ${ }^{[27]}$, indicating the importance of post-translational modifications of BACE1. Future studies will determine whether PIMT-induced methylation of BACE1 at aspartyl residues increases its enzyme activity.

In conclusion, we have demonstrated that knock-down of PIMT increased $A \beta$ production via the inhibition of the nonamyloidogenic a-secretase pathway, an effect that is linked to a decrease in SAPPa and ADAM10/17 levels as summarized in Figure 4 . Therefore, our study suggests a novel protective

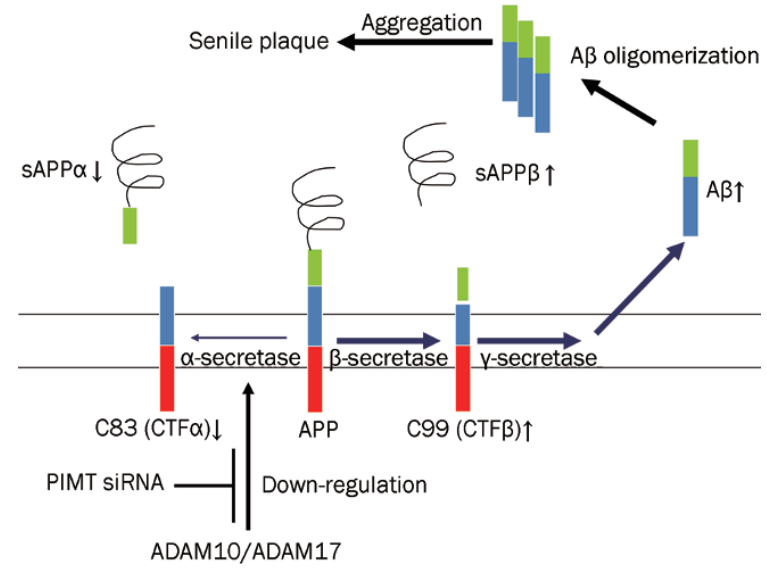

Figure 4. Proposed mechanism of action for PIMT in the regulation of $A \beta_{40}$ peptide generation. $A \beta$ peptides are generated from APP by $\beta$ and $\gamma$-secretase activity. PIMT seems to modulate the levels of $\alpha$ - and $\beta$-secretases synthesized from ADAM10- and -17.

role for PIMT in the pathogenesis of $\mathrm{AD}$ as a negative regulator of $\mathrm{A} \beta_{40}$ peptide formation.

\section{Acknowledgements}

This research was supported by Technology Development Program for Agriculture and Forestry, Ministry for Food, Agriculture, Forestry and Fisheries, Republic of Korea.

\section{Author contribution}

Narkhyun BAE, Jae Youl CHO, and Sungyoul HONG designed research; Narkhyun BAE, Se Eun BYEON, Jihyuk SONG, and Sang-Jin LEE performed research; Moosik KWON and Inhee MOOK-JUNG analyzed data.

\section{References}

1 Dodart JC, May P. Overview on rodent models of Alzheimer's disease. Curr Protoc Neurosci 2005; Chapter 9: Unit 9.22.

2 Hardy J, Selkoe DJ. The amyloid hypothesis of Alzheimer's disease: progress and problems on the road to therapeutics. Science 2002; 297: 353-6.

3 De Strooper B, Saftig P, Craessaerts K, Vanderstichele H, Guhde G, Annaert W, et al. Deficiency of presenilin-1 inhibits the normal cleavage of amyloid precursor protein. Nature 1998; 391: 387-90.

4 Buxbaum JD, Liu KN, Luo Y, Slack JL, Stocking KL, Peschon JJ, et al. Evidence that tumor necrosis factor alpha converting enzyme is involved in regulated alpha-secretase cleavage of the Alzheimer amyloid protein precursor. J Biol Chem 1998; 273: 27765-7.

5 Grillo MA, Colombatto S. S-adenosylmethionine and its products. Amino Acids 2008; 34: 187-93.

6 Kennedy BP, Bottiglieri T, Arning E, Ziegler MG, Hansen LA, Masliah E. Elevated S-adenosylhomocysteine in Alzheimer brain: influence on methyltransferases and cognitive function. J Neural Transm 2004; 111: 547-67.

7 Sontag E, Nunbhakdi-Craig V, Sontag JM, Diaz-Arrastia R, Ogris E, Dayal S, et al. Protein phosphatase 2A methyltransferase links homocysteine metabolism with tau and amyloid precursor protein regulation. J Neurosci 2007; 27: 2751-9.

8 Bottiglieri T. S-Adenosyl-L-methionine (SAMe): from the bench to the 
bedside - molecular basis of a pleiotrophic molecule. Am J Clin Nutr 2002; 76: 1151S-7S.

9 Yamamoto A, Takagi $\mathrm{H}$, Kitamura D, Tatsuoka H, Nakano H, Kawano H, et al. Deficiency in protein $L$-isoaspartyl methyltransferase results in a fatal progressive epilepsy. J Neurosci 1998; 18: 2063-74.

10 Shimizu T, Watanabe A, Ogawara M, Mori H, Shirasawa T. Isoaspartate formation and neurodegeneration in Alzheimer's disease. Arch Biochem Biophys 2000; 381: 225-34.

11 Shimizu T, Matsuoka Y, Shirasawa T. Biological significance of isoaspartate and its repair system. Biol Pharm Bull 2005; 28: 15906.

12 Kim CM, Hong WS, Lee JO, Kang TW, Kim YH, Cho CG, et al. A retrospective study on radiotherapy and radiochemotherapy in esophageal cancer. Korean J Intern Med 1988; 3: 58-63.

13 Kim JY, Lee YG, Kim MY, Byeon SE, Rhee MH, Park J, et al. Src-mediated regulation of inflammatory responses by actin polymerization. Biochem Pharmacol 2010; 79: 431-43.

14 Paris D, Ganey NJ, Laporte V, Patel NS, Beaulieu-Abdelahad D, Bachmeier $\mathrm{C}$, et al. Reduction of beta-amyloid pathology by celastrol in a transgenic mouse model of Alzheimer's disease. J Neuroinflammation 2010; 7: 17.

15 Iwatsubo T. Pathogenesis of Alzheimer's disease: implications from amyloid research front. Rinsho Shinkeigaku 2004; 44: 768-70.

16 Okamura N, Arai H, Higuchi M, Tashiro M, Matsui T, Itoh M, et al. Cerebrospinal fluid levels of amyloid beta-peptide1-42, but not tau have positive correlation with brain glucose metabolism in humans. Neurosci Lett 1999; 273: 203-7.

17 Mills J, Reiner PB. Regulation of amyloid precursor protein cleavage. J Neurochem 1999; 72: 443-60.

18 Citron M, Oltersdorf T, Haass C, McConlogue L, Hung AY, Seubert $\mathrm{P}$, et al. Mutation of the beta-amyloid precursor protein in familial Alzheimer's disease increases beta-protein production. Nature 1992; 360: 672-4.
19 Liu F, Su Y, Li B, Ni B. Regulation of amyloid precursor protein expression and secretion via activation of ERK1/2 by hepatocyte growth factor in HEK293 cells transfected with APP751. Exp Cell Res 2003; 287: 387-96.

20 Hong S, Heo J, Lee S, Heo S, Kim SS, Lee YD, et al. Methyltransferaseinhibition interferes with neuronal differentiation of P19 embryonal carcinoma cells. Biochem Biophys Res Commun 2008; 377: 935-40.

21 Obregon DF, Rezai-Zadeh K, Bai Y, Sun N, Hou H, Ehrhart J, et al. ADAM10 activation is required for green tea (-)-epigallocatechin3-gallate-induced alpha-secretase cleavage of amyloid precursor protein. J Biol Chem 2006; 281: 16419-27.

22 Camden JM, Schrader AM, Camden RE, Gonzalez FA, Erb L, Seye Cl, et al. P2Y2 nucleotide receptors enhance alpha-secretase-dependent amyloid precursor protein processing. J Biol Chem 2005; 280 : 18696-702.

23 Kins S, Lauther N, Szodorai A, Beyreuther K. Subcellular trafficking of the amyloid precursor protein gene family and its pathogenic role in Alzheimer's disease. Neurodegener Dis 2006; 3: 218-26.

24 Massone S, Argellati F, Passalacqua M, Armirotti A, Melone L, d'Abramo $C$, et al. Downregulation of myosin II-B by siRNA alters the subcellular localization of the amyloid precursor protein and increases amyloidbeta deposition in N2a cells. Biochem Biophys Res Commun 2007; 362: 633-8.

25 Li Y, Zhou W, Tong Y, He G, Song W. Control of APP processing and Abeta generation level by BACE1 enzymatic activity and transcription. FASEB J 2006; 20: 285-92.

26 Cheng H, Vetrivel KS, Drisdel RC, Meckler X, Gong P, Leem JY, et al. S-palmitoylation of gamma-secretase subunits nicastrin and APH-1. J Biol Chem 2009; 284: 1373-84.

27 Kang EL, Cameron AN, Piazza F, Walker KR, Tesco G. Ubiquitin regulates GGA3-mediated degradation of BACE1. J Biol Chem 2010; 285: 24108-19. 